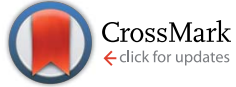

Cite this: RSC Adv., 2014, 4, 47894

\title{
Ultrasound assisted synthesis of a Zn(II) metal- organic framework with nano-plate morphology using non-linear dicarboxylate and linear $\mathrm{N}$-donor ligands $\uparrow$
}

\begin{abstract}
Mohammad Yaser Masoomi, ${ }^{a}$ Ali Morsali*a and Peter C. Junk ${ }^{\text {b }}$
A 3D, porous $Z n(॥)$-based metal-organic framework $\left\{\left[Z_{2}(o b a)_{2}(4-b p d b)\right] \cdot 2 D M F\right\}_{n}(T M U-4)$ with double interpenetration was prepared by using a non-linear dicarboxylate $\left(\mathrm{H}_{2} \mathrm{Oba}=4,4^{\prime}\right.$-oxybisbenzoic acid $)$ and a linear $\mathrm{N}$-donor (4-bpdb =1,4-bis(4-pyridyl)-2,3-diaza-1,3-butadiene) ligand. Also micro- and nano-plates of this MOF were synthesized by a sonochemical process and characterized by scanning electron microscopy, X-ray powder diffraction and IR spectroscopy. The thermal stability was studied by thermogravimetric analysis (TGA). Sonication time and concentration of initial reagents effects on the size and morphology of nano-structured MOFs, were studied. Calcination of TMU-4 at $500{ }^{\circ} \mathrm{C}$ under air atmosphere yields $\mathrm{ZnO}$ nanoparticles.
\end{abstract}

Received 24th August 2014

Accepted 22nd September 2014

DOI: $10.1039 / \mathrm{c} 4 \mathrm{ra0} 0186 \mathrm{~h}$

www.rsc.org/advances

involves formation, growth, and instantaneously implosive

\section{Introduction}

Three-dimensional (3D) metal-organic frameworks (MOFs) are a new class of porous materials which are highly attractive because of their potential use as functional materials in structure-dependent applications, such as gas storage and separation, ion exchange, sensing, catalysis, and drug delivery. ${ }^{1-8}$ The MOFs can be designed by choosing appropriate organic ligands and inorganic secondary building units (SBUs). ${ }^{9}$

Of the many ligands that have been employed for the preparation of MOF structures, using a combination of functionalized dicarboxylic acids and N-donor ligands can lead to MOFs with desired properties., ${ }^{5,10,11}$ Meanwhile, there is also an increasing interest in MOFs with flexible and dynamic frameworks with appropriate groups in their structures to exhibit high selectivity for guest inclusion and structural transformation upon adsorption/desorption of guest molecules. ${ }^{12,13}$

Reducing the size of MOFs to nanoscale has been extremely attractive. ${ }^{4}$ Recently using ultrasound irradiation in synthesis and preparation of nano or microstructures of MOFs has been of interest. ${ }^{14-17}$ In the research area of sonochemistry molecules undergo a chemical reaction because of the application of powerful ultrasound radiation $(20 \mathrm{KHz}-10 \mathrm{MHz})^{18}$ which induce chemical or physical changes during cavitation. Cavitation

${ }^{a}$ Department of Chemistry, Faculty of Sciences, Tarbiat Modares University, Tehran, Islamic Republic of Iran. E-mail: morsali_a@modares.ac.ir; Tel: +98-21-82883449

${ }^{b}$ College of Science, Technology \& Engineering, James Cook University, Townsville, Queensland 4811, Australia

$\dagger$ Electronic supplementary information (ESI) available: Other figures, full synthetic and analytical details. CCDC 996860. For ESI and crystallographic data in CIF or other electronic format see DOI: 10.1039/c4ra09186h collapse of bubbles in a liquid, which generates local hot spots having temperatures up to $5000{ }^{\circ} \mathrm{C}, 500 \mathrm{~atm}$ pressures with a lifetime of a few microseconds. ${ }^{19-21}$ These extreme conditions can also enhance the formation of nano-sized structures, mostly via an increase of crystallization nuclei. ${ }^{22}$

$\mathrm{ZnO}$ is a polar inorganic material and an important n-type semiconductor with a wide band gap energy of $3.37 \mathrm{eV},{ }^{23}$ and is an excellent material for potential applications including solar cells, luminescent materials, transparent conductors and gas sensors. ${ }^{24-28}$ Up until now, various synthetic methods have been developed to produce zinc oxide nanostructures. ${ }^{29,30}$ Thermal decomposition of MOFs under various conditions has been widely studied for the preparation of $\mathrm{ZnO}$ nanostructures with different sizes and morphologies. ${ }^{31}$

In this work, we have synthesized a Zn(II) metal-organic framework based on a V-shaped flexible dicarboxylate ligand, 4,4'-oxybis(benzoic acid) $\left(\mathrm{H}_{2} \mathrm{Oba}\right)$ and the $\mathrm{N}$-donor ligand 1,4bis(4-pyridyl)-2,3-diaza-1,3-butadiene (4-bpdb) and investigated the effect of ultrasonic irradiation on shape and size. Also TMU4 was calcined at $500{ }^{\circ} \mathrm{C}$ to prepare $\mathrm{ZnO}$ nanoparticles.

\section{Experimental}

\section{Materials and physical techniques}

All reagents for the synthesis and analysis were commercially available from Aldrich and Merck Company and used as received. The ligand 4-bpdb (1,4-bis(4-pyridyl)-2,3-diaza-1,3butadiene) was prepared by the reported method. ${ }^{32}$ Melting points were measured on an Electrothermal 9100 apparatus. IR spectra were recorded using Thermo Nicolet IR 100 FT-IR. 
Ultrasonic generation was carried out in an ultrasonic bath SONICA-2200 EP (frequency of $40 \mathrm{KHz}$ ). The samples were characterized with a field emission scanning electron microscope (FE-SEM) Philips XL30 and TESCAN MIRA (Czech) with gold coating.

The thermal behaviour was measured with a PL-STA 1500 apparatus with the rate of $10^{\circ} \mathrm{C} \mathrm{min}^{-1}$ in a static atmosphere of argon. X-ray powder diffraction (XRD) measurements were performed using a Philips X'pert diffractometer with mono chromated $\mathrm{Cu}-\mathrm{K}_{\alpha}$ radiation.

Single crystals of TMU- 4 were coated with viscous hydrocarbon oil and mounted on a loop. Data were obtained at $-173{ }^{\circ} \mathrm{C}(100 \mathrm{~K})$ on the MX1: Macromolecular Crystallography beamline at the Australian Synchrotron, Victoria, Australia. Data collection and integration on the MX1: Macromolecular Crystallography beamline were carried out using Blu-Ice ${ }^{33}$ and the XDS software package. ${ }^{34}$ The structure was solved using SHELXS $^{35}$ and refined by full-matrix least-squares on all F2 data using SHELX, ${ }^{35}$ in conjunction with the X-Seed graphical user interface. ${ }^{36}$ All hydrogen atoms were placed in calculated positions using the riding model. Sorption study on TMU-4 was performed using the AutosorbIQ from Quantachrome Instruments: $\mathrm{CO}_{2}$ at $195 \mathrm{~K}$. The sample was activated at $140{ }^{\circ} \mathrm{C}$ for 12 hours under vacuum. Dynamic light scattering measurements of particle sizes were determined by means of a Zetasizer Nano equipment.

\section{Synthesis of $\left\{\left[\mathrm{Zn}_{2}(\mathrm{oba})_{2}(\mathbf{4}-\mathrm{bpdb})\right] \cdot 2 \mathrm{DMF}\right\}_{n}$ (TMU-4)}

Conventional heating. Single crystals of TMU-4 suitable for X-ray diffraction were prepared by mixing $\mathrm{Zn}\left(\mathrm{NO}_{3}\right)_{2} \cdot 6 \mathrm{H}_{2} \mathrm{O}$ (0.297 g, $1 \mathrm{mmol}), \mathrm{H}_{2} \mathrm{Oba}(0.254 \mathrm{~g}, 1 \mathrm{mmol})$ and 4 -bpdb $(0.105 \mathrm{~g}$, $0.5 \mathrm{mmol}$ ) in $30 \mathrm{~mL}$ of DMF. This mixture was sonicated until all solids were uniformly dispersed $(\sim 3 \mathrm{~min})$, and it was then heated at $80{ }^{\circ} \mathrm{C}$. After 72 hours, yellow crystals of TMU-4 were collected $\left(0.420 \mathrm{~g}\right.$, yield $71 \%$ based on oba), d.p. $>300^{\circ} \mathrm{C}$. IR data (KBr pellet, $\left.\nu / \mathrm{cm}^{-1}\right)$ : selected bands: 776(s), 875(m), 1089(s), $1159(\mathrm{~s}), 1241(v \mathrm{~s}), 1412(v \mathrm{~s}-\mathrm{br}), 1500(\mathrm{~s}), 1608(v \mathrm{~s}), 1679(v \mathrm{~s})$ and 3417 (w-br). Elemental analysis (\%) calculated for $\left[\mathrm{Zn}_{2}\left(\mathrm{C}_{14} \mathrm{O}_{5^{-}}\right.\right.$ $\left.\left.\mathrm{H}_{8}\right)_{2}\left(\mathrm{C}_{12} \mathrm{H}_{10} \mathrm{~N}_{4}\right)\right]\left(\mathrm{C}_{3} \mathrm{NOH}_{7}\right)_{2}$ : C: $55.3, \mathrm{H}: 4.0, \mathrm{~N}: 8.4$; found: C: 55.8, H: 3.8, N: 8.2.
Synthesis of TMU-4 nanostructure. Ultrasonic syntheses of TMU-4 were carried out in an ultrasonic bath at ambient temperature and atmospheric pressure for 30, 60 and $90 \mathrm{~min}$ with different concentrations of metal and ligands, respectively. The resulting powder was isolated by centrifugation, washed with DMF three times and dried in air for characterization (Table 1). The effect of triethylamine (TEA) was investigated by adding 2 and $3 \mathrm{~mL}$ of TEA to adjust pH to 6 and 7, respectively.

\section{Results and discussion}

Yellow crystals of TMU-4 were synthesized by mixing $\mathrm{H}_{2} \mathrm{Oba}$, $\mathrm{Zn}\left(\mathrm{NO}_{3}\right)_{2} \cdot 6 \mathrm{H}_{2} \mathrm{O}$ and 4 -bpdb in DMF solvent at $80{ }^{\circ} \mathrm{C}$ for 3 days.

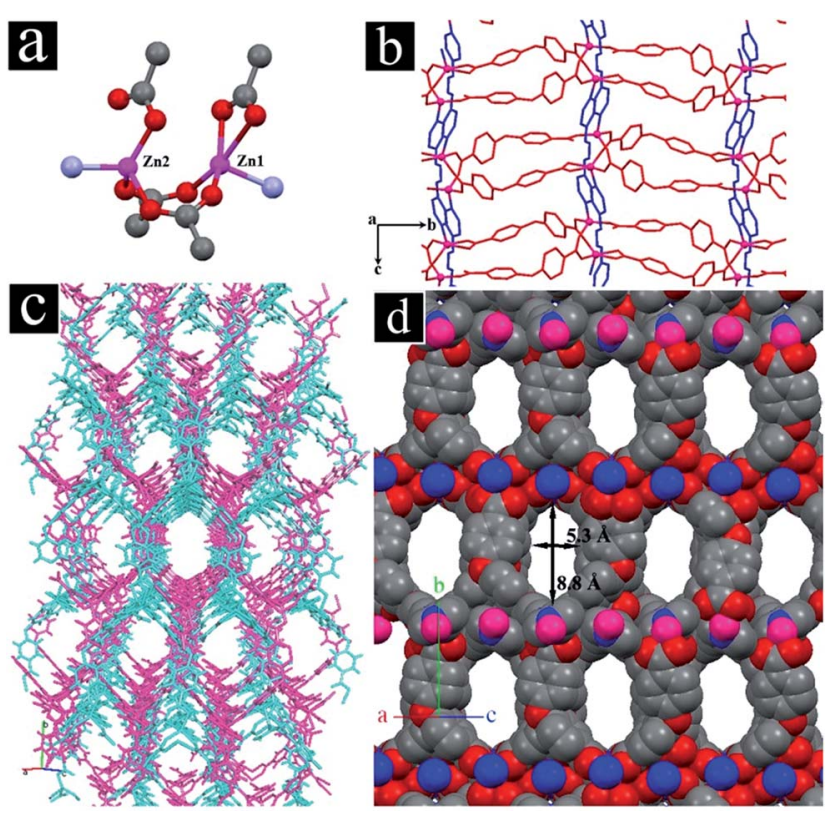

Fig. 1 (a) Ball and stick representation of the binuclear $Z \mathrm{n}_{2}$ unit (O: red; $\mathrm{N}$ : blue; C: grey; and Zn: pink). (b) Layers of Zn(II)-oba (in red) pillared by $4-b p d b$ (in blue). (c) Representation showing the pore channels and that the network is doubly interpenetrated (in pink and blue). (d) Spacefill representation shows aperture size of pores along [101] direction. Hydrogen atoms and DMF molecules are omitted for clarity.

Table 1 Experimental details for synthesis of nano TMU-4

\begin{tabular}{|c|c|c|c|c|c|c|}
\hline $\begin{array}{l}\text { Samples } \\
\text { name }\end{array}$ & $\begin{array}{l}\text { Molar ratio } \\
\left(\text { oba }: 4 \text {-bpdb }: \mathrm{Zn}(\mathrm{OAc})_{2}\right) \\
\text { mmol in } 25 \mathrm{~mL} \mathrm{DMF}\end{array}$ & $\begin{array}{l}\text { Concentration } \\
{[\mathrm{oba}] /[4 \mathrm{bpdb}] /} \\
{\left[\mathrm{Zn}(\mathrm{OAc})_{2}\right](\mathrm{M})}\end{array}$ & Time (min) & $\begin{array}{l}\text { Elemental analysis, } \\
\text { found }^{a}(\%)\end{array}$ & Yield (\%) & Morphology \\
\hline A & $1: 1: 0.6$ & {$[0.04] /[0.04] /[0.024]$} & 30 & C: $55.8, \mathrm{H}: 3.7, \mathrm{~N}: 8.4$ & 75 & Micro plate \\
\hline B & $1: 1: 0.6$ & {$[0.04] /[0.04] /[0.024]$} & 60 & C: $55.6, \mathrm{H}: 3.8, \mathrm{~N}: 8.1$ & 80 & Micro plate \\
\hline $\mathrm{C}$ & $1: 1: 0.6$ & {$[0.04] /[0.04] /[0.024]$} & 90 & C: $55.4, \mathrm{H}: 3.9, \mathrm{~N}: 8.2$ & 85 & Micro plate \\
\hline $\mathrm{D}$ & $1.5: 1.5: 0.9$ & {$[0.06] /[0.06] /[0.036]$} & 90 & C: $55.6, \mathrm{H}: 3.9, \mathrm{~N}: 8.5$ & 82 & Micro plate \\
\hline $\mathrm{E}$ & $0.5: 0.5: 0.3$ & {$[0.02] /[0.02] /[0.012]$} & 90 & C: $55.9, \mathrm{H}: 3.8, \mathrm{~N}: 8.3$ & 88 & Micro plate \\
\hline $\mathrm{F}$ & $0.5: 0.5: 0.3$ & $\begin{array}{l}{[0.02] /[0.02] /[0.012]} \\
\text { TEA }=2 \mathrm{~mL}, \mathrm{pH}=6\end{array}$ & 90 & $\mathrm{C}: 55.4, \mathrm{H}: 3.7, \mathrm{~N}: 8.4$ & 56 & Nano plate \\
\hline G & $0.5: 0.5: 0.3$ & $\begin{array}{l}{[0.02] /[0.02] /[0.012],} \\
\text { TEA }=3 \mathrm{~mL}, \mathrm{pH}=7\end{array}$ & 90 & $\mathrm{C}: 55.2, \mathrm{H}: 3.6, \mathrm{~N}: 8.0$ & 51 & Nano plate \\
\hline
\end{tabular}


Single-crystal X-ray diffraction reveals that TMU-4 crystallized in the space group $P 2_{1} / c$ with the formula of $\left\{\left[\mathrm{Zn}_{2}(\mathrm{oba})_{2}(4-\mathrm{bpdb})\right]\right.$. $2 \mathrm{DMF}\}_{n} \cdot{ }^{37}$ TMU-4 is based on a binuclear $\mathrm{Zn}_{2}$ unit ( $\mathrm{Zn \# 1}$ and

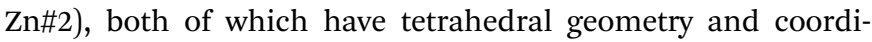
nated to three carboxylate $\mathrm{O}$ atoms (for $\mathrm{Zn \# 1:O2,} \mathrm{O7,} \mathrm{O10,} \mathrm{and}$ for $\mathrm{Zn \# 2:} \mathrm{O1,} \mathrm{O5,} \mathrm{O6)} \mathrm{from} \mathrm{three} \mathrm{adjacent} \mathrm{oba} \mathrm{ligands} \mathrm{and} \mathrm{one} \mathrm{N}$ atom (Zn\#1: N4 and Zn\#2: N1) from the 4-bpdb ligand (Fig. 1a). The distance between $\mathrm{Zn \# 1}$ and $\mathrm{Zn \# 2}$ is $3.358 \AA$. Each nonlinear $\left(\mathrm{C}-\mathrm{O}-\mathrm{C}=118.0(6)^{\circ}\right)$ dicarboxylate oba ligand binds three consecutive $\mathrm{Zn}$ (II) centers from two different units: one carboxylate group of an oba ligand adopts a bidentate mode and bridges both $\mathrm{Zn \# 1}$ and $\mathrm{Zn \# 2}$ centers of the unit while the other

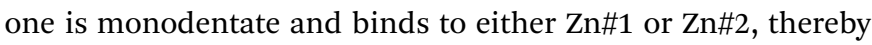
forming $2 \mathrm{D}$ sheets (Fig. 1b). The 2D sheets are connected through the linear 4 -bpdb, extending the structure in three dimensions. The V-shaped coordination of the oba ligand plays an important role in the linkage of the nodes resulting in a three-dimensional honeycomb framework with double interpenetration (Fig. 1c). Although the double interpenetration is formed to avoid an extremely large void space, but still possesses one-dimensional (1D) open channels (aperture size: $5.3 \times 8.8 \AA$, taking into account the van der Waals radii; $35.9 \%$ void space per unit cell $)^{38}$ running along the [101] direction and
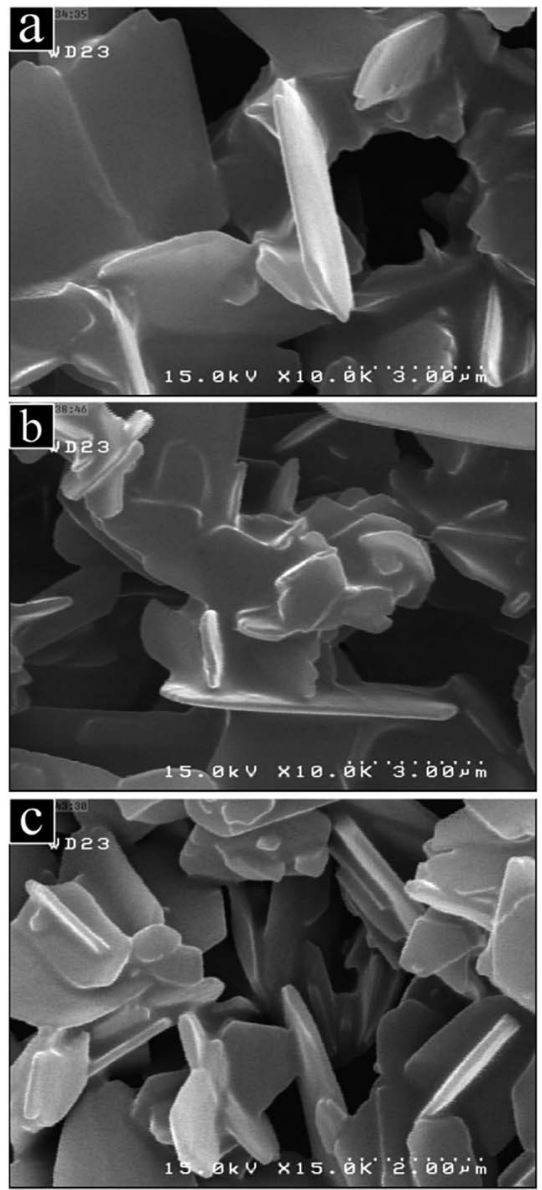

Fig. 2 FE-SEM images of nano-plates of TMU-4 synthesized by sonochemical reaction (a) sample $A$, (b) sample $B$ and (c) sample $C$. lattice DMF molecules are accommodated in the channels (Fig. 1d). TMU-4 is porous to $\mathrm{CO}_{2}$ at $195 \mathrm{~K}$ and 1 bar $\left(148.90 \mathrm{~cm}^{3} \mathrm{~g}^{-1}\right.$ at $1 \mathrm{bar}$; BET surface area calculated over $p / p^{0}=$ 0.02-0.3: $517.9 \mathrm{~m}^{2} \mathrm{~g}^{-1}$ ) (Fig. S2, ESI $\dagger$ ). The pore volume calculated from the $\mathrm{CO}_{2}$ adsorption is $0.298 \mathrm{~cm}^{3} \mathrm{~g}^{-1} \cdot 39$

The morphology and size of TMU-4 were investigated using scanning electron microscopy (SEM) by changing two parameters; sonication time and concentration of starting materials as well as control of nucleation.
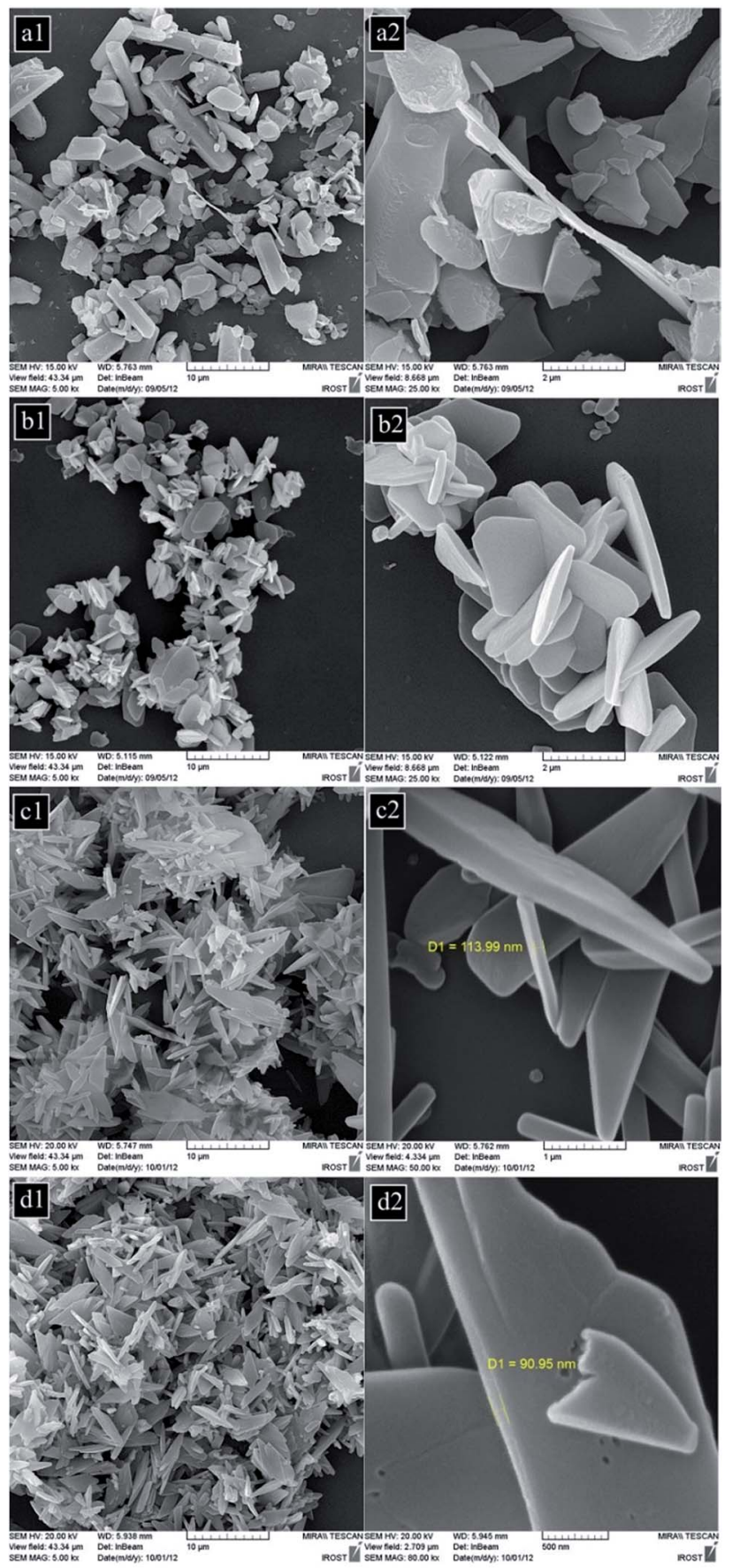

Fig. 3 FE-SEM images of nano-plates of TMU-4 synthesized by sonochemical reaction (a) sample D, (b) sample E, (c) sample F and (d) sample $G$. 
Firstly, sonication time as a parameter was changed at constant concentration of [0.04] $\mathrm{M}$ of starting materials. In all three different times (30, 60 and $90 \mathrm{~min}$ ) micro-plates of TMU-4 were obtained in which higher sonication time (90 $\mathrm{min}$ ) leads to uniform distribution in plate size (Fig. 2 and S3, ESI $\dagger$ ). Hence, sonication time of $90 \mathrm{~min}$ is considered as the optimized value.

After this in order to investigate the role of concentration of initial reagents on the morphology and size of product, reactions were performed with two different concentrations of starting materials $([0.06] \mathrm{M}$ and $[0.02] \mathrm{M})$. The results show that high concentrations of initial reagents increased particle size and thus lower concentration of initial reagents reduced the size of plates (Fig. 3). After this, increasing the speed of nucleation during the synthesis of TMU-4 was tested by adding triethylamine (TEA). Using TEA causes fast nucleation of product due to deprotonated oba ligand and faster nucleation reduces particle size. In this mechanism nano-plates with a narrow size distribution were obtained (Fig. $3 \mathrm{c}$ and d). ${ }^{22}$ By this, width of nano-plate reduces to $90 \mathrm{~nm}$ (Fig. 3d).

The IR spectra of both crystals produced by conventional heating and nano-plate produced by the sonochemical method show the symmetric $\nu_{\text {sym }}$ (COO) and asymmetric $\nu_{\text {as }}$ (COO) vibrations of the carboxylate groups at $1409 \mathrm{~cm}^{-1}$ and $1604 \mathrm{~cm}^{-1}$, respectively. Also the characteristic absorption peak $\left(\nu_{\mathrm{C}=\mathrm{O}}=1679 \mathrm{~cm}^{-1}\right)$ of DMF are presented in the IR spectra of TMU-4 (Fig. S4, ESI $\dagger$ ).

A comparison between powder X-ray diffraction (PXRD) patterns of the simulated (derived from the single crystal structure of TMU-4) and experimental (resulting from the sonochemical process) confirms that the sonochemically synthesized TMU-4 is structurally identical to TMU-4 prepared through conventional heating (Fig. 4).

To examine the thermal stability of TMU-4 thermogravimetric analysis (TGA) was carried out between 25 and $600{ }^{\circ} \mathrm{C}$. The TGA curve of TMU-4 (conventional heating) shows a plateau in the range of 25 to $100{ }^{\circ} \mathrm{C}$ followed by a continuous loss of $14.5 \%$ (expected: $14.6 \%$ ) up to $305^{\circ} \mathrm{C}$, which can be ascribed to removal of the guest DMF molecules (Fig. 5).

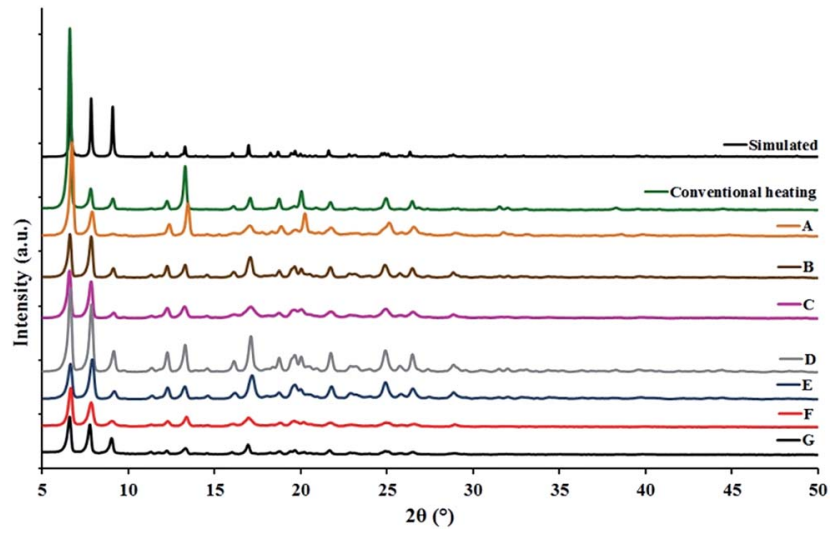

Fig. 4 XRD patterns of TMU-4 prepared by either conventional heating or sonochemical reaction (samples $A-G$ ). The data are in good agreement with the simulated pattern derived from the corresponding single-crystal structure data.

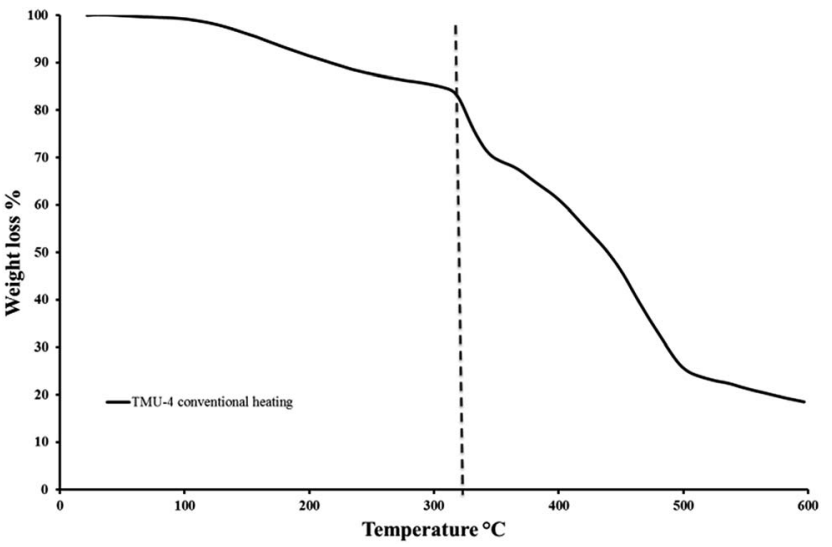

Fig. 5 Thermogravimetric profiles of TMU-4 isolated conventional heating.

Decomposition of TMU-4's framework occurs in the temperature range of $305-500{ }^{\circ} \mathrm{C}$. Final residual mass $18.4 \%$ (expected: 19\%) and the XRD pattern of the final decomposition product show the formation of $\mathrm{ZnO}$ (Fig. S5, ESI $\dagger$ ).

To prepare zinc oxide nanoparticles, TMU-4 was calcined at $500{ }^{\circ} \mathrm{C}$ for $2 \mathrm{~h}$. Fig. S5† depicts the XRD patterns of the residue obtained from calcination of TMU-4. The Bragg diffraction peaks in the range of $2 \theta=20-80^{\circ}$ exhibit the typical patterns of hexagonal wurtzite structure of $\mathrm{ZnO}$ consistent with the reported data by the JCPDS card number 36-1451 with lattice parameters of $a=3.25$ and $c=5.20 \AA$. The SEM image of the residue obtained from the direct calcination of TMU-4 at $500{ }^{\circ} \mathrm{C}$ shows the formation of $\mathrm{ZnO}$ nanoparticle (Fig. 6).

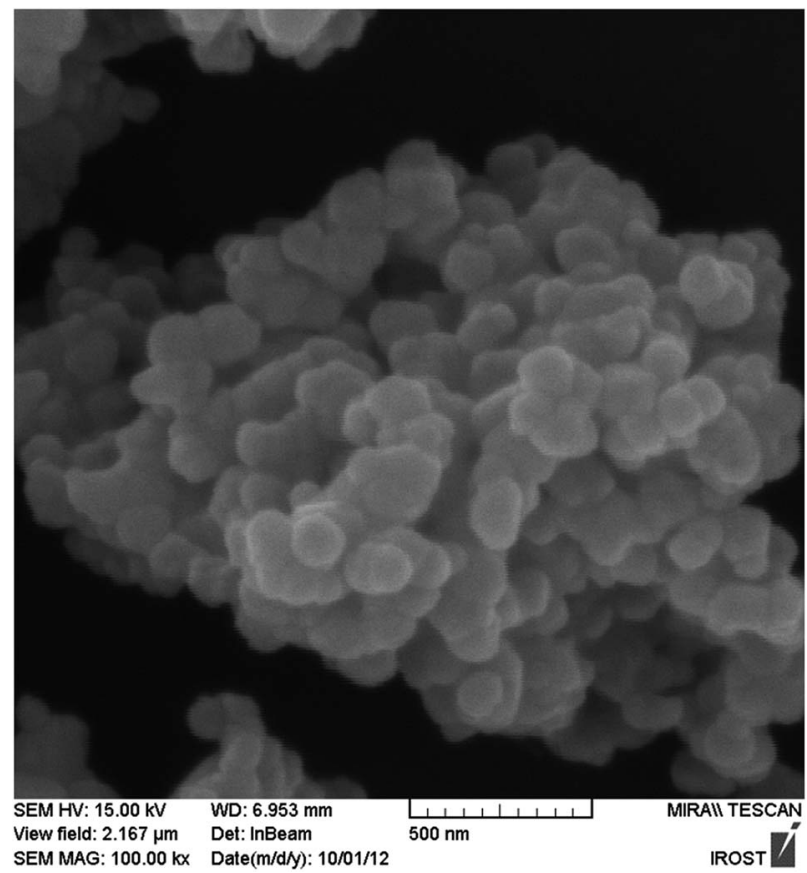

Fig. 6 FE-SEM image of $\mathrm{ZnO}$ nanoparticles prepared by thermolysis of $\mathrm{TMU}-4$ at $500^{\circ} \mathrm{C}$. 


\section{Conclusions}

A $3 \mathrm{D}$, porous metal-organic framework $\left\{\left[\mathrm{Zn}_{2}(\mathrm{oba})_{2}(4-\mathrm{bpdb})\right]\right.$. $2 \mathrm{DMF}\}_{n}$ (TMU-4) with double interpenetration was synthesized by conventional heating and analysed by X-ray crystallography. Using ultrasonic irradiation leads to formation of micro- and nano-plates of TMU-4 that were characterized by scanning electron microscopy, X-ray powder diffraction and IR spectroscopy. To prepare the nanostructure of TMU-4, three different times and concentrations of initial reagents, [0.06], [0.04] and [0.02] M, were tested. Also the rate of nucleation was tested by adding TEA to the reaction. Results show that best uniform distribution of nano-plates TMU-4 were obtained in $90 \mathrm{~min}$ with concentration of [0.02] $\mathrm{M}$ in the presence of TEA. These results indicate that sonochemical process can be used as an effective method for fast and readily preparation of nano-MOFs. Also calcination of TMU-4 at $500{ }^{\circ} \mathrm{C}$ under air atmosphere yields $\mathrm{ZnO}$ nanoparticles.

\section{Acknowledgements}

Support of this investigation by Tarbiat Modares University is gratefully acknowledged.

\section{Notes and references}

1 E. Lallana, A. Sousa-Herves, F. Fernandez-Trillo, R. Riguera and E. Fernandez-Megia, Pharm. Res., 2012, 29, 1-34.

2 Z. Ma and B. Moulton, Coord. Chem. Rev., 2011, 255, 16231641.

3 M. Y. Masoomi and A. Morsali, Coord. Chem. Rev., 2012, 256, 2921-2943.

4 M. Y. Masoomi and A. Morsali, RSC Adv., 2013, 3, 1919119218.

5 A. Corma, H. García and F. X. Llabrés i Xamena, Chem. Rev., 2010, 110, 4606-4655.

6 M. P. Suh, H. J. Park, T. K. Prasad and D.-W. Lim, Chem. Rev., 2011, 112, 782-835.

7 L. E. Kreno, K. Leong, O. K. Farha, M. Allendorf, R. P. Van Duyne and J. T. Hupp, Chem. Rev., 2011, 112, 1105-1125.

8 P. Horcajada, R. Gref, T. Baati, P. K. Allan, G. Maurin, P. Couvreur, G. Férey, R. E. Morris and C. Serre, Chem. Rev., 2011, 112, 1232-1268.

9 N. Stock and S. Biswas, Chem. Rev., 2011, 112, 933-969.

10 R. Kitaura, K. Seki, G. Akiyama and S. Kitagawa, Angew. Chem., Int. Ed., 2003, 42, 428-431.

11 P. Mahata, M. Prabu and S. Natarajan, Cryst. Growth Des., 2009, 9, 3683-3691.

12 R. Vaidhyanathan, S. S. Iremonger, G. K. H. Shimizu, P. G. Boyd, S. Alavi and T. K. Woo, Science, 2010, 330, 650653.

13 K. C. Stylianou, J. E. Warren, S. Y. Chong, J. Rabone, J. Bacsa, D. Bradshaw and M. J. Rosseinsky, Chem. Commun., 2011, 47, 3389-3391.

14 N. Soltanzadeh and A. Morsali, Ultrason. Sonochem., 2010, 17, 139-144.
15 M. J. S. Fard-Jahromi and A. Morsali, Ultrason. Sonochem., 2010, 17, 435-440.

16 A. Aslani and A. Morsali, Inorg. Chim. Acta, 2009, 362, 50125016.

17 M. Y. Masoomi, G. Mahmoudi and A. Morsali, J. Coord. Chem., 2010, 63, 1186-1193.

18 K. S. Suslick, S.-B. Choe, A. A. Cichowlas and M. W. Grinstaff, Nature, 1991, 353, 414-416.

19 R. Feng, Y. Zhao, C. Zhu and T. J. Mason, Ultrason. Sonochem., 2002, 9, 231-236.

20 M. Strasberg, J. Acoust. Soc. Am., 1959, 31, 163-176.

21 K. Negishi, J. Phys. Soc. Jpn., 1961, 16, 1450-1465.

22 D. Tanaka, A. Henke, K. Albrecht, M. Moeller, K. Nakagawa, S. Kitagawa and J. Groll, Nat. Chem., 2010, 2, 410-416.

23 P. X. Gao, Y. Ding and Z. L. Wang, Nano Lett., 2003, 3, 13151320.

24 K. Keis, L. Vayssieres, S.-E. Lindquist and A. Hagfeldt, Nanostruct. Mater., 1999, 12, 487-490.

25 Y. Dai, Y. Zhang, Q. K. Li and C. W. Nan, Chem. Phys. Lett., 2002, 358, 83-86.

26 M.-C. Jeong, B.-Y. Oh, W. Lee and J.-M. Myoung, Appl. Phys. Lett., 2005, 86, 103105.

27 M. Bagheri, N. F. Hamedani, A. R. Mahjoub, A. A. Khodadadi and Y. Mortazavi, Sens. Actuators, B, 2014, 191, 283-290.

28 M. Bagheri, A. A. Khodadadi, A. R. Mahjoub and Y. Mortazavi, Sens. Actuators, B, 2013, 188, 45-52.

29 K. T. Johnson, T. E. Gribb, E. M. Smoak and I. A. Banerjee, Chem. Commun., 2010, 46, 1757-1759.

30 H. T. Ng, J. Li, M. K. Smith, P. Nguyen, A. Cassell, J. Han and M. Meyyappan, Science, 2003, 300, 1249.

31 M. Y. Masoomi and A. Morsali, Coord. Chem. Rev., 2012, 256, 2921-2943.

32 D. M. Ciurtin, Y.-B. Dong, M. D. Smith, T. Barclay and H.-C. zur Loye, Inorg. Chem., 2001, 40, 2825-2834.

33 T. M. McPhillips, S. E. McPhillips, H.-J. Chiu, A. E. Cohen, A. M. Deacon, P. J. Ellis, E. Garman, A. Gonzalez, N. K. Sauter, R. P. Phizackerley, S. M. Soltis and P. Kuhn, J. Synchrotron Radiat., 2002, 9, 401-406.

34 W. Kabsch, J. Appl. Crystallogr., 1993, 26, 795-800.

35 G. Sheldrick, Acta Crystallogr., Sect. A: Cryst. Phys., Diffr., Theor. Gen. Crystallogr., 2008, 64, 112-122.

36 L. J. Barbour, J. Supramol. Chem., 2001, 1, 189-191.

37 Crystal data for TMU-4: $\mathrm{C}_{42.25} \mathrm{H}_{31.25} \mathrm{~N}_{4.75} \mathrm{O}_{10.75} \mathrm{Zn}_{2}, M=$ 908.21, monoclinic, space group $P 22_{1} / c, a=12.344(3) \AA$ A,$b=$ 26.323(5) А, $c=15.663(3) \AA, \beta=97.56(3)^{\circ}, V=5045.2(18)$ $\AA^{3}, Z=4$, crystal size $\left(\mathrm{mm}^{3}\right): 0.12 \times 0.08 \times 0.01, T=$ $173(2) \mathrm{K}, D_{\text {calc. }}=1.196 \mathrm{~g} \mathrm{~cm}^{-3}, R_{1}=0.0936, \mathrm{w}_{2}=0.2706$, 59356 reflections measured, 11143 unique $\left(R_{\text {int }}=0.0560\right)$, $R_{1}=0.1156, \mathrm{w} R_{2}=0.2866$ (all data), GOF on $F 2=1.049$, $F(000)=1856, \mu=1.004 \mathrm{~mm}^{-1}, D_{\rho \max }=1.171 \mathrm{e}^{-3}$

38 A. L. Spek, J. Appl. Crystallogr., 2003, 36, 7-13.

39 M. Y. Masoomi, K. C. Stylianou, A. Morsali, P. Retailleau and D. Maspoch, Cryst. Growth Des., 2014, 14, 2092-2096. 